\title{
Reply: Transfers vs. Economic Costs of the Iraq War
}

\section{JOSEPH STIGLITZ}

The letter by Anthony D'Amato rais$\perp$ es an important point. Whether the payments are transfer payments to the shareholders of Bechtel and Halliburton does not affect our estimate of the budgetary costs, but does effect conclusions about the economic costs of the war in Iraq. Some of the payments may not really be payments for "resources used," which was part of our attempted calculation of economic costs, if they represent payments beyond the normal return on capital and other factors of production. Such payments rightly should be considered transfer payments from American taxpayers as a whole to shareholders of Bechtel and Halliburton. These may well be significant, but we have not so far been able to separately identify them.

By the same token, our study identified the costs to the American economy as a whole of increased oil prices. But in addition to these costs, there are large transfers-from ordinary Americans to the oil companies, the one group that has done very well indeed by the war. Had we focused on the cost of the war to the typical American-excluding the oil companies - the costs would have, accordingly, been even higher.

Joseph E. Stiglitz

University Professor, Columbia University, New York, New York, U.S.A. 


\section{REFERENCES AND FURTHER READING}

Stiglitz, Joseph (2006) "The High Cost of The Iraq War", The Economists' Voice: Vol. 3:

No. 3, Article 5, available at

D'Amato, Anthony (2006) "Letter: Transfer Payments vs. Economic Costs in the Iraq War", The Economists' Voice: Vol. 3: No. 4, Article 6, available at 